vaccine storage. Particular attention should be given to training of people responsible for vaccine storage, in the use and care of equipment such as maximum and minimum thermometers and thermostat controls. The maximum and minimum storage temperatures should be recorded daily irrespective of the type of refrigerator, and the thermostat should be adjusted when temperatures are outside the recommended range. Thirdly, use of the refrigerator for storing other items should be minimised to avoid frequent opening of the door, and, fourthly, local guidelines should address the safe storage of vaccines during transportation.

The cold chain for vaccines is a vulnerable point for the immunisation programme. Ensuring that each phial of vaccine is maintained under appropriate conditions until used will safeguard the programme's success.

We thank Dr G Roland, Central Manchester Health Authority, for her advice and support; Dr I Ferguson,
Haworth Surgeries; and all those who participated in the survey.

1 Longland P, Rowbottom P. Room temperature stability of medicines recommended per cold storage. Pharmaceutical fournal 1989;4:584-94.

2 Sokhey J, Gupta CJ, Sharma B, Singh H. Stability of oral polio vaccine at different temperature. Vaccine 1988:6:12-3.

3 Manufacturers recommendations regarding stability of vaccines at room temperatures. London: Smith, Kline and French, 1990

4 World Health Organisation. Expanded programme on immunisation-stability of vaccines. Geneva: WHO, 1989.

Department of Health Joint Committee on Vaccination and Immunisation. Immunisation against infectious disease. London: HMSO, 1990.

Immunisation against infectious disease. London. HMSO, 1990. Manchester: CMHA, 1990:6-7.

7 Lugosi L, Battersby A. Transport and storage of vaccines in Hungary. Bull World Health Organ 1990;68:431-3.

8 Expanded programme on immunisation-cold chain evaluation. Wkly Epidemiol Rec 1990;65:181-4.

9 Expanded programme on immunisation: the effects of freezing on the appearance, potency, and toxicity of adsorbed and unadsorbed DPT vaccines. Wkly Epidemiol $R e c$ 1980;55:385-9, 396-8.

10 McLean AA, Shaw R. Hepatitis B virus vaccine. Ann.Intern Med 1982;97:451. 11 Hunter S. Storage of vaccines in general practice. BMJ 1989;299:661-2.

(Accepted 16 fanuary 1991)

\title{
Asthma care in Darley Dale: general practitioner audit
}

\author{
Cedrick R Martys
}

\begin{abstract}
Objective-To complete a first audit cycle of asthma care in Darley Dale after starting an asthma clinic.
\end{abstract}

Design-Pre-clinic (1989) and post-clinic (1990) analysis of medical records of patients with asthma.

Setting-A group practice in Derbyshire.

Patients-161 pre-clinic, 238 post-clinic patients with asthma.

Main outcome measures-Term "asthma" in the patient's computerised problem list, recording of peak expiratory flow rate, smoking history, clinical review, medication, and hospital admissions for asthma.

Results-There were significant improvements post-clinic with respect to the term "asthma" in the computer file (1989, 93/161 (58\%); 1990, 233/238 (98\%) (difference $0.40 ; 95 \%$ confidence interval 0.32 to 0.48$)$ ); at least one peak flow measurement (1989, $24 / 161(15 \%) ; 1990,143 / 238(60 \%)(0.45 ; 0.37$ to $0.53)$ ); three or more peak flow measurements $(1989$, $15 / 161(9 \%) ; 1990,40 / 238(17 \%)(0.08 ; 0.02$ to 0.14$))$; and smoking history $(1989,24 / 161(15 \%) ; 1990$, $133 / 238(56 \%)(0.41 ; 0.33$ to 0.49$))$. There were no significant differences post-clinic with respect to asthma reviewed at least once $(1989,61 / 161(38 \%)$; $1990,74 / 238(31 \%)(0.07 ;-0.03$ to 0.17$))$; recording long term medication; treating acute asthma; or ratio of average to best peak flow rate of 38 .patients who had one or more measurements $(1989,31 / 38(82 \%)$; $1990,34 / 38(89 \%)(0.08 ;-0.08$ to 0.24$))$.

Conclusions - Setting up an asthma clinic resulted in better recording of data relevant to patients with asthma. However, objective improvement in patients' asthma could not be detected. Renewed emphasis on prophylactic measures may result in measurable improvement in these patients' asthma in the future.

Centre, Darley Dale,

Matlock, Derbyshire DE4 2SA

Cedrick R Martys, MD, general practitioner

Correspondence to: Cedrick R Martys.

BMf 1992;304:758-60

\section{Introduction}

Asthma is a common illness in the United Kingdom; $6 \%$ of the population have asthma, and it is responsible for 2000 deaths a year. ${ }^{1}$ It is estimated that more than $10 \%$ of children have asthma and that the prevalence, severity, and mortality have increased in recent years in both adults and children. ${ }^{23}$ Suboptimal care in general practice has contributed to this state of affairs. ${ }^{45}$ Recently guidelines on the management of asthmatic patients have been published. ${ }^{267}$ These provide detailed recommendations for prophylaxis and management of acute and chronic asthma, but it is too early to evaluate their impact on the care of asthmatic patients in the community.

For many years we have held special clinics in the Darley Dale practice for patients with hypertension and diabetes, and, although these have not been the subject of any formal audit procedures, we believed that better care was provided for patients attending these clinics than was the case previously. In 1989 we had felt for some time that we were not providing optimal care for our asthmatic patients, and when my trainee at the time expressed an interest in the management of asthma we worked to produce a practice protocol, which led to the establishment of an asthma clinic.

The aim of this audit was to ascertain whether better care has been provided for our asthmatic patients as a result of setting up the asthma clinic.

\section{Subjects and methods}

This training partnership of four principals is based in semirural west Derbyshire. The practice maintains three fully equipped surgeries, but the audit of asthma care was restricted to patients attending our main medical centre in Darley Dale. The pre-clinic audit and setting up of the asthma clinic were undertaken by Beverley Howson as a trainee project submitted for the local Syntex essay competition. The post-clinic audit was undertaken by me.

\section{PRE-CLINIC AUDIT}

Patients with asthma were identified by searching the practice computerised medical records for the term "asthma" in the computer problem list and searching the medication record for any record of long term treatment that is commonly prescribed to patients with asthma-for example, salbutamol or beclomethasone dipropionate inhalers. Patients so identified were sent a letter (addressed to the parents of subjects under 18) inviting them to attend the surgery for a consultation 
concerning their asthma. An encounter form was designed for use at this initial consultation to record details of the patient's age and sex, height, weight, and expected and actual peak expiratory flow rates. The best of three readings was recorded. Details of the patient's current medication were recorded (including any not in the computer medication record), technique of inhaler use was assessed and corrected if necessary, a smoking history was obtained, and any admissions to hospital for asthma in the past year were recorded. The purpose of the asthma clinic was explained and an invitation to attend the clinic was given.

\section{ASTHMA CLINIC PROTOCOL}

At the first consultation in the asthma clinic the emphasis is on patient education. The nature of the illness is described, along with an explanation of the way in which medication for asthma works, with emphasis on the importance of good technique and compliance. Patients are taught how to recognise deterioration in their symptoms (usual treatment no longer helps, increasing difficulty in performing everyday tasks, sleep disturbed by cough or wheeze, deterioration in peak expiratory flew rate) and advised what action they should take. To help prevent asthma symptoms patients are advised to stop smoking, avoid trigger factors, and use a prophylactic bronchodilator before exercise. The peak expiratory flow rate (best of three) is measured at each visit. The need for continuous inhaled steroids or intermittent oral steroids is assessed on an individual basis. If oral steroids are likely to be required patients are given a one week course of prednisolone with instructions to commence these as recommended at the start of an asthma attack.

An asthma diary card is issued to each patient. This records long term diurnal variations in peak expiratory flow rate, symptoms attributable to asthma, and changes in medication. Patients are asked to bring their diary cards with them when they return to the asthma clinic. After the initial visit patients are seen at six monthly intervals if their asthma is well controlled, or more frequently if there are difficulties with inhaler technique or in controlling symptoms or signs

\section{POST-CLINIC AUDIT}

After the asthma clinic had been in operation for one year a review of the care provided for asthmatic patients since the clinic was set up was undertaken,

TABLE I - Audit measurements before and after establishment of asthma clinic

\begin{tabular}{|c|c|c|c|c|c|c|}
\hline Criterion & $\begin{array}{l}\text { Standard } \\
(\%)\end{array}$ & $\begin{array}{l}\text { Pre-clinic } \\
(\text { No }(\%))\end{array}$ & $\begin{array}{l}\text { Post-clinic } \\
(\text { No }(\%))\end{array}$ & Difference & $\begin{array}{l}95 \% \text { Confidence } \\
\text { interval }\end{array}$ & $\mathrm{p}$ Value \\
\hline $\begin{array}{l}\text { "Asthma" in computer } \\
\text { problem list }\end{array}$ & 100 & $93 / 161(58)$ & $233 / 238(98)$ & $0 \cdot 40$ & 0.32 to 0.48 & $<0.001$ \\
\hline $\begin{array}{l}\text { PEFR at least once in previous } \\
\text { year } \\
\text { PEFR three times or more in }\end{array}$ & 100 & $24 / 161(15)$ & $143 / 238(60)$ & $0 \cdot 45$ & 0.37 to 0.53 & $<0.001$ \\
\hline $\begin{array}{l}\text { previous year } \\
\text { Smoking history recorded } \\
\text { Clinical review at least once }\end{array}$ & $\begin{array}{r}50 \\
100\end{array}$ & $\begin{array}{l}15 / 161(9) \\
24 / 161(15)\end{array}$ & $\begin{array}{r}40 / 238(17) \\
133 / 238(56)\end{array}$ & $\begin{array}{l}0 \cdot 08 \\
0 \cdot 41\end{array}$ & $\begin{array}{l}0.02 \text { to } 0.14 \\
0.33 \text { to } 0.49\end{array}$ & $\begin{array}{l}<0.05 \\
<0.001\end{array}$ \\
\hline $\begin{array}{l}\text { Wat least once } \\
\text { year } \\
\text { edication for }\end{array}$ & 100 & $1 / 161(38)$ & $74 / 238(31)$ & 0.07 & -0.03 to 0.17 & 0.05 \\
\hline $\begin{array}{l}\text { asthma readily identified } \\
\text { No of courses of oral steroids } \\
\text { No of administrations of }\end{array}$ & 100 & $\begin{array}{c}161 / 161(100) \\
26 / 161(16)\end{array}$ & $\begin{array}{c}238 / 238(100) \\
53 / 238(22)\end{array}$ & $\begin{array}{l}0 \\
0 \cdot 06\end{array}$ & -0.02 to $0 \cdot 14$ & $>-$ \\
\hline $\begin{array}{l}\text { salbutamol nebulisation } \\
\text { Ratio of average to best PEFR }\end{array}$ & $\overline{80}$ & $\begin{array}{l}11 / 161(7) \\
31 / 38(82)\end{array}$ & $\begin{array}{l}24 / 238(10) \\
34 / 38(89)\end{array}$ & $\begin{array}{l}0 \cdot 03 \\
0 \cdot 07\end{array}$ & $\begin{array}{l}-0.02 \text { to } 0.08 \\
--0.08 \text { to } 0.24\end{array}$ & $\begin{array}{l}>0.05 \\
>0.05\end{array}$ \\
\hline
\end{tabular}

PEFR $=$ Peak expiratory flow rate.

TABLE II -Age distributions of patients with asthma on practice lists in 1989 and 1990

\begin{tabular}{lcccccccc}
\hline & \multicolumn{1}{c}{ Age (years) } \\
\cline { 2 - 10 } & $<10$ & $10-19$ & $20-29$ & $30-39$ & $40-49$ & $50-59$ & $60-69$ & $\geqslant 70$ \\
\hline No on list in 1989 & 12 & 31 & 19 & 26 & 17 & 17 & 18 & 21 \\
No on list in 1990 & 29 & 49 & 26 & 38 & 30 & 20 & 21 & 25 \\
\hline
\end{tabular}

especially with regard to the standards for good asthma care listed in table I. The records of patients with the term "asthma" in the computer problem list were identified and the proportion of all asthmatic patient records so labelled compared with the proportion identified before starting the clinic one year previously (standard required $100 \%$ ). The number of patients who had at least one (standard $100 \%$ ) or three or more (standard 50\%) peak flow measurements in the previous year, pre-clinic and post-clinic, was identified. Smoking history was recorded (standard 100\%). A similar comparison was made regarding the time since the patient last had a consultation for asthma entered in the record (standard 100\% within the previous year), the ease of identification of long term treatment for asthma (standard $100 \%$ ), and the number of short term courses of $\beta_{2}$ agonists and oral steroids administered. As peak expiratory flow rate is an objective measure of the severity of a patient's asthma good care was also defined as at least $80 \%$ of asthmatic patients having a ratio of average to best peak expiratory flow rates better than $80 \%$. Finally, the number of admissions to hospital of patients with acute asthma during the period under study was identified.

Data were analysed by $\chi^{2}$ test with one degree of freedom and Yates's correction, and confidence intervals were calculated.

\section{Results}

A comparison of pre-clinic and post-clinic audited parameters is shown in table I. The number of known asthmatic patients on the Darley Dale practice list of 4100 patients in 1989 (pre-clinic) was 161 , a prevalence of $4 \%$. At the end of 1990, 238 patients with asthma had been identified, a post-clinic prevalence of $6 \%$. In $1989,93(58 \%)$ of the patients were male and $68(42 \%)$ female, and in 1990, $137(58 \%)$ were male and 101 $(42 \%)$ female. The age distribution of patients with asthma in 1989 and 1990 is shown in table II.

Term "asthma" in computer problem list-In 1989, 93 out of $161(58 \%)$ asthmatic patients had the term asthma entered in the computer problem list. In 1990 233 out of $238(98 \%)$ were so identified (difference 0.40 $(95 \%$ confidence interval 0.32 to 0.48$) ; \chi^{2}=86.6$, $\mathrm{p}<0.001)$

Peak flow measurements-In 1989, 24 out of 161 (15\%) patients, and in 1990,143 out of $238(60 \%)$, had had at least one peak flow reading entered in the medical records in the previous year (difference 0.45 (95\% confidence interval 0.37 to 0.53 ); $\chi^{2}=78.5$, $\mathrm{p}<0.001)$. In 1989,15 out of $161(9 \%)$ patients, and in 1990,40 out of $238(17 \%)$, had had three or more peak flow readings recorded in the previous year (difference $0.08(0.02$ to 0.14$\left.) ; \chi^{2}=3.93, \mathrm{p}<0.05\right)$.

Smoking history-In 1989, 24 out of $161(15 \%)$ patients, and in 1990,133 out of $238(56 \%)$, had their smoking history recorded (difference 0.41 (95\% confidence interval 0.33 to 0.49$) ; \gamma^{2}=66.0, \mathrm{p}<0.001$ ).

Asthma reviewed clinically-In 1989, 61 out of 161 (38\%) patients, and in 1990,74 out of $238(31 \%)$, had had their asthma reviewed clinically at least once in the previous year (difference 0.07 ( $95 \%$ confidence interval -0.03 to 0.17$\left.) ; \chi^{2}=1.68, \mathrm{p}>0.05\right)$.

Long term medication - In 1989 all 161 patients, and in 1990 all 238, had their long term medication $\left(\beta_{2}\right.$ agonists and inhaled steroids) recorded in the practice computer system for repeat medication.

Acute medication-Short courses of drugs administered for acute asthma were recorded in the general clinical record of the patient's computer file.

Number of courses of oral steroids prescribed - In 1989 for 161 asthmatic patients 26 courses of oral steroids were prescribed, and in 1990 for 238 patients 53 courses of steroids were prescribed (difference 0.06 
(95\% confidence interval -0.02 to $0 \cdot 14) ; \chi^{2}=1 \cdot 9$, $\mathrm{p}>0.05$ ). Some patients received more than one course of steroids during each year.

Number of times salbutamol nebulisation was administered - In 1989 for 161 patients 11 courses and in 1990 for 238 patients 24 courses of salbutamol nebulisation were administered to patients with acute asthma (difference 0.03 (95\% confidence interval -0.02 to $\left.0.08) ; \chi^{2}=0.88, p>0.05\right)$. Some patients had nebulisation on more than one occasion during each year.

Peak flow measurements: average versus best-Of 38 patients who had one or more peak flow readings taken in both 1989 and 1990, the ratio of average to best readings was better than $80 \%$ in $31(82 \%)$ patients in 1989 and $34(89 \%)$ patients in 1990 (difference 0.07 (95\% confidence interval -0.08 to 0.24$) ; \chi^{2}=0.42$, $\mathrm{p}>0.05$ ).

Admissions to hospital with acute asthma-Four emergency hospital admissions were made for patients with acute asthma in each year.

\section{Discussion}

Before undertaking this first audit exercise on the care of patients with asthma in Darley Dale we had little knowledge of who our asthmatic patients were, how severe their asthma was, and what treatment they were receiving. As a direct result of setting up the asthma clinic and discussions on the protocol for management of asthmatic patients that were a prerequisite for this, we can now identify our asthmatic patients much more easily as almost all of them now have the term "asthma" entered in their computer problem list. The importance of making a formal diagnosis of asthma and entering this term in the records has been shown by Gellert et al. ${ }^{8}$ We now have better information regarding the smoking habits of our asthmatic patients, and more of our patients have more peak flow readings recorded than was the case before starting the clinic. Long term medication for asthma was well recorded before the clinic started. The practice has for several years had a computerised medication file for all patients receiving continuous drug treatment over many months or years, and drugs for asthma were recorded in this file.

Bell et al have shown that although the introduction of audit in the hospital care of acute asthma may improve processes such as clerking and record keeping, it may result in relatively little improvement in clinical care. ${ }^{9}$ However, Charlton et al reported an improvement in illness due to asthma in both adults and children after starting a nurse run asthma clinic. ${ }^{10}$ Although we found an improvement in record keeping as a result of starting the asthma clinic, almost certainly due in part to the wider awareness of asthma among members of the practice team, overall clinical improvement among our asthmatic patients proved much more difficult to detect. Good prophylaxis against asthma should be associated with a reduction in the number of courses of oral steroids and salbutamol nebulisation administered for acute attacks, yet we were unable to show such a reduction. This may have been associated with improved education and greater awareness of the potentially lifesaving effect of these drugs in acute severe asthma and a readiness to use them more frequently and earlier in an attack. The availability of more nebulisers in the practice-we now have six compared with one two years ago - may also be a factor.

\section{INDICATIONS OF IMPROVED STANDARDS}

One outcome measure we considered to be a good indicator of improved standards of care as a result of starting the asthma clinic would be a demonstration of overall improvement in patients' peak expiratory flow rate. We felt that in at least $80 \%$ of our asthmatic patients the ratio of average to best peak expiratory flow rate should be better than $80 \%$. In both years under review this was shown to be the case, although improvement found after the clinic was started was not statistically significant. This ratio was chosen as a more realistic measure than average to predicted peak expiratory flow rate would have been as many asthmatic patients never approach their predicted peak expiratory flow rate, taking account of their age, height, and sex, even when they are well. Although the peak flow meter has been regarded as not crucial to the management of asthma, ${ }^{1}$ it does provide a valuable objective indicator of the presence and severity of asthma. ${ }^{12}$

Another good outcome measure of the effectiveness of intensive monitoring and education of patients in a general practitioner asthma clinic would be a reduction 0 in the number of hospital admissions for patients with $\nRightarrow$ acute asthma. This audit found the same number of $\vec{\nabla}$ patients admitted to hospital in 1989 and in 1990. A longer term review will be needed if asthmatic patients are to be shown to require less hospitalisation as a result of regular attendance at an asthma clinic.

One disappointing feature of this audit shows that proportionately fewer patients were reviewed with $₫$ respect to their asthma in 1990, after the clinic had started, than in 1989. This was mainly due to each two N hour clinic session rapidly becoming fully booked as some patients with poorly controlled asthma required $\infty$ frequent repeat attendances. Additionally, many more $ᄋ$ asthmatic patients were identified in 1990 than were $N$ known in 1989.

Failure to see every patient with asthma within the first year of starting the clinic and difficulties in showing improved clinical care in terms of reduced requirement of drugs used in treating acute asthma and $\notin$ reduced hospital admissions have emerged in this first audit of asthma care in Darley Dale. As a result of this study our management of asthmatic patients will in the future concentrate on obtaining a higher annual attendance rate at the clinic, with renewed emphasis on prophylactic measures. We are also considering starting $\mathbb{\perp}$ a second weekly clinic. A future repeat of this audit $\bar{\partial}$ cycle will monitor these activities further, and the 3 activity of the asthma clinic will be re-evaluated in the light of subsequent measured outcomes along these lines.

I thank Beverley Howson for her work in setting up the Darley Dale asthma clinic during her attachment to the practice as my trainee; Heather Silvers, community nurse, for her help with the week to week running of the clinic; and John Hadfield, consultant chest physician, Chesterfield and North Derbyshire Royal Hospital, for his helpful suggestions and $\mathrm{O}$ comments.

1 Burney PGJ Asthma mortality in England and Wales: evidence for an for an $\frac{D}{2}$

2 Warner JO, Götz M, Landau LI, Levison H, Milner AD, Pedersen S, et al. Management of asthma: a consensus statement. Arch Dis Child 1989;64: 1065-79.

3 Fleming DM, Crombie DL. Prevalence of asthma and hay fever in England and Wales. BMF 1987;294:279-83.

4 Jones $\mathrm{K}$. Asthma care in general practice-time for revolution? $\mathrm{Br} f \mathrm{Gen}$ Pract 1991;41:224-6.

5 Jan Heijne Den Bak. Prevalence and management of asthma in children under 16 in one practice. BMF 1986;292:175-6.

6 British Thoracic Society. Guidelines for management of asthma in adults. I. T Chronic persistent asthma. BMF 1990;301:651-3.

7 British Thoracic Society. Guidelines for management of asthma in adults. 11. Acute severe asthma. BM7 1990;301:797-800.

8 Gellert AR, Gellert SL, lliffe SR. Prevalence and management of asthma in a London inner city general practice. Br f Gen Pract 1990;40:197-201. 9 Bell D, Layton AJ, Gabbay J. Use of a guideline based questionnaire to audit

10 Charlton I, Charlton G, Broomfield J, Mullee MA. Audit of the effect of a Charlton I, Charlton G, Broomfield J, Mullee MA. Audit of the effect of a
nurse run asthma clinic on workload and patient morbidity in a general practice. Br F Gen Pract 1991;41:227-31.

11 Charlton I, Charlton G, Broomfield J, Mullee MA. Evaluation of peak flow and symptoms only self management plans for control of asthma in general practice. BMF 1990;301:1355-9.

12 Turner-Warwick $M$. Nocturnal asthma: a study in general practice. $B r f$ Gen Pract 1989;39:239-43.

(Accepted 3 fanuary 1992) 